\title{
Prospective Structural Method Application to Identify Strategic Variable of Developing Ecotourism Region in Reservoir Area
}

\author{
Nafiah Ariyani ${ }^{1}$, Tanjung Prasetya ${ }^{2}$, Kurniawan Gilang ${ }^{3}$ \\ Sahid University Jakarta, J1. Prof.Dr.Soepomo, SH. No, 84, South Jakarta, Indonesia 1,2,3 \\ ariyani12@gmailcom ${ }^{1}$, tprasetya@gmail.com², gilang20@gmail.com ${ }^{3}$
}

\begin{abstract}
Designing ecotourism areas in the reservoir area requires a multidisciplinary approach to identifying strategic variables that will determine its success. This study aims to determine the most influential variables in the development of the Kedung Ombo reservoir ecotourism area. Data analysis uses a prospective structural approach with the help of Micmac software. Data collection uses focus group discussion methods and workshops involving stakeholders in the Kedung Ombo dam. The group discussion agreed that there are 33 variables that must be considered in the development of the Kedung Ombo ecotourism area with typology as follows: Input Variables, consisting of: regulation, integration with surrounding land use local awareness of tourism, infrastructure, local entrpreneurship ability, potential of tourism market, tourism actraction, economic potential of tourism business, and community involvement; Relay Variables, consisting of: policy for special permit for invenstment, retribution policy, tax policy, allowance policy, tourism promotion, apparatus role, governance, private investment, and coordination; 3) Autonomous Variables, consisting of: climite, security, natural beauty, developer anderstanding of local norms, potential conflict, and accesibilty. 4) Results Variables, consisting of: fund for community, preservation of local wisdom, employment expansion, forest preservation, concervation of reservoir function, improvement of welfare, and reduction of poverty. The results of this study will be a rich source of information for policy makers in the Kedung Ombo reservoir in developing it as a sustainable ecotourism area.
\end{abstract}

Keywords: Ecotourism, Sustainability, Structural, Prospective, Micmac

\section{Introduction}

Tourism is a complex system, on the one hand it is a socio-economic phenomenon that is significantly spatially separated and bound to the attractiveness of local conditions, on the other hand is a phenomenon that requires high coordination and cooperation from all stakeholders [1]. From the aspect of development, tourism is considered as a reliable sector that is environmentally friendly with a high level of effectiveness of job creation and income. This 
condition requires that tourism development needs proper planning supported by a comprehensive analysis of the future so that sustainable tourism is realized.

Based on this thinking tourism studies closer to a multi-disciplinary approach, in order to characterize the multiple factors that affect social, institutional and economic dynamics as well as their mutual interrelations. The persistence of such multi-disciplinary approach may reflect a common intuition over the existence of pluralities of tourism which cannot be fully captured by means of mono-disciplinary analysis. At a mono-disciplinary approach, tourism is traditionally assessed as the sum of its constituent parts, this is due to a lack of categories and analytical tools that exceed the mono-disciplinary analysis. This weakness clearly shows the dilemma between comprehensive perceptions of tourism and how to overcome it to produce comprehensive and capable scientific knowledge in the future[2].

If we aims at assessing tourism as a complex, systemic and evolutionary reality, its analysis will requires a tools that allow us to take into account its heterogeneous constituent elements, their mutual non-linear interrelations as well as its dynamic nature. As well as y considering the impacts in the whole of any eventual change in any of the constituent elements, non-linear reciprocal relationships and dynamic nature. Beside that, considering the impact on overall system changes as a result of occurs in one of its constituent elements, and is able to describe the future situation of an object. To achieve these goals, a prospective analysis is proposed.

One potential area that can become a tourist attraction is the reservoir area. Utilizing the reservoir area and its resource for tourism was a rational thing. This matter had been quite successful in several cases in China and other countries [3]. Their research recommended that the development of tourism around reservoir could be done as long as it could realize a harmonization between human, nature, social and economic development in a sustainable manner. This is to ensure that the important task of the reservoir must be maintained well, such as: flood storage and disposal, water volume adjustment, electricity generation, water supply for industry and agriculture and life in the city. If tourism arrangement in this area were not appropriate, the serious consequences were not measurable anymore. Therefore, it was necessary to have an appropriate planning supported by a comprehensive analysis of the future in order to make it realize a sustainable tourism.

Kedung Ombo Reservoir is one of the largest reservoirs in Southeast Asia owned by Indonesia, with an inundation area of $\pm 4,500 \mathrm{Ha}$ and a normal reservoir volume of 723 Million M3. However, since 2003 this reservoir has experienced massive siltation (an average of 0.87 $\mathrm{m}^{3}$ per year) due to significant sedimentation. Sedimentation occurs because of the conversion of land around the river and economic activities of other local residents in the reservoir. It is feared that it will disrupt the sustainability of the main function of the reservoir as a flood controller. Therefore, it is necessary to look for alternative activities that can provide economic benefits but are safe for the sustainability of the reservoir function. The alternative that we offer is developing ecotourism in the reservoir area.

Ecotourism which prioritizes aspects of nature conservation, aspects of socio-economic empowerment of local communities and aspects of learning and education are very appropriate to be developed. To provide input to decision makers about strategic variables that must be the focus in developing the Kedung ombo reservoir ecotourism area, this research was conducted. The results of the study allow the formation of quality long-term policy recommendations, avoiding problems and encourage future thinking in the management of the Kedung Ombo reservoir as an ecotourism area. 


\section{Method}

\section{a. Desain Research}

The research was designed based on a prospective research paradigm in the context of future thinking.

\subsection{Data Collection}

Data collection method was carried out using focus group discussion and workshop. In order to encourage the active involvement of all discussion participants is needed in prospective structural analysis. The structural analysis work process is carried out through participatory workshops and deliberations[4]. This allows comprehensive recommendations to be found before a decision is made. The discussions were held using world café method. This method will to drive the occurrence knowledge sharing and experience transfer processes among participants.

The participants of the discussion were twenty people representing the stakeholders of the Kedung Ombo Reservoir. The twenty participants consisted ofomprising the Head and Operational Director of Balai Besar Wilayah Sungai (BBWS) Pemali Juana as the reservoir operator, Bappeda officials, Head of Sports and Tourism Youth Services Departement from Grobogan, Boyolali and Sragen district, lecturers from tourism college in Solo city, students, tourism service businessmen and community around reservoir. The focus group discussions was aimed at finding strategic variables in the development of the Kedung ombo reservoir ecotourism. Before having discussion, some interviews were held with the Head of Balai Besar Wilayah Sungai (BBWS) Pemali Juana, the Administrator of Perum Perhutani, the Head of SubDisctrict around reservoir area, the Village Head of the nearest village from the reservoir, community around reservoir area and community who had visited the reservoir to explore the possibility of the idea of Kedung Ombo ecotourism region development.

\subsection{Data Analysis}

Data analysis was carried out based on the concept of prospective structural analysis. Prospective structural analysis is a method that is based on the development of future scenarios based on historical trends of a system. Prospective structural analysis is a robust method for identifying key variables (driver domain) and studying the relationship between dependent and independent variables of a system[2]. The main purpose of this method is to reduce future uncertainties, build possible or desired scenarios and encourage the actions needed to achieve them. Prospective analysis will be able to capture the existence of complex strategic factors and their independent relationships, which are needed to realize a long-term quality development strategy, avoiding problems that may arise in the future, encourage future thinking and develop knowledge warehouses for policy maker or decision itself.

Prospective analysis techniques assume that the future is different from the past and not forced, but can be built. Prospective structural analysis techniques will analyze the complexity of the elements, factors and its relationship and to understand key variables of system in the current and future situations. The relationship between these variables is a rich source of information that will determine thinking about some problems in this future context [5]. Through structural analysis, even many variable functions will be identified so that it makes it easier for decision makers to determine the right policies.

A prospective structural analysis is carried out by a work committee consisting of actors and experts from the field under study without excluding external advisors[4]. The structural analysis was initially is philosophical and qualitative, but later changed and operationalized into a variety of quantitative methods stated that structural analysis has distinct advantages from 
other analyzes such as factor, namely: allowing expert groups to find methods for sharing ideas among group members, giving group members the opportunity to explain views and thoughts about problems certain [5].

The main advantage of structural analysis is that it stimulates thinking and generates ideas among group members, thus encouraging them to think about counter-intuitive aspects of how the system works. However as a method of analysis for the future, prospective structural analysis has several disadvantages, namely: it depends on a small group of participants (maximum 12 people), inefficient in terms of time, costs and human resources, and is based on a single value. These things will hinder the space of imagination and innovation that is very important for longterm views and thinking. In addition, the results are very likely to be biased. The limitations of the subjective nature of structural analysis stem from the fact that this analysis is not reality but a means of seeing reality. This tool allows for the discovery of idea collection methods by reducing bias that is inevitable. Based on these weaknesses, Arcade and Godet built a modern prospective structural analysis was called Micmac (Cross-Impact Matrix Multiplication Applied to Classification) [5]. Finally, structural analysis is a long process that sometimes becomes an end in itself so it should not be done except by the subject itself.

The structural analysis method was very useful as a decision making support, operational planning, impact determining of a strategy and the future evaluation alternative and it was operated in a matrix form. The structural analysis was structured in three stages. The first two stages were carried out during the workshops and the third stage was carried out using Micmac software. Those stages can be seen in Fig. 1 below.

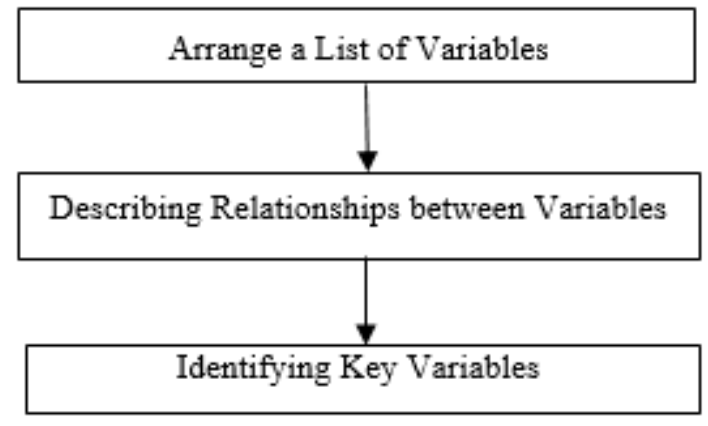

Fig. 1. Stages of strutural analysis [2].

The structural analysis had advantages that were different from another analysis, namely: allowing expert group to find a method for sharing ideas among group members, giving group members an opportunity to explain their views and thoughts about a particular problem[5]. In the Kedung Ombo case, this method can not only describe the current situation but also allows describing the scenario through stimulating and compiling a process of collective reflection to build the future vision of the Kedung Ombo region and to highlight the actions needed to achieve it. However, as an analysis method for the future, the said structural analysis had several weaknesses, namely: relying on a small group of participants (maximum 12 people), it was inefficient in terms of time, cost and human resource and single value-based. In addition, the result was probably refracted. Based on the weaknesses, Arcade and Godet built a modern structural analysis called Micmac (Cross-Impact Matrix Multiplication Applied to Classification) [5].

Micmac is software was arranged to apply prospective structural analysis was developed by Institute d'Innovation Informatique pour I'Entreprise, under the supervision of Laboratory of 
Investigation in Prospective Start and Organization (LIPSOR)[5];[4]. This software applied matrix property to determine variable suitable to the number of their path and intensity[6][5]. Through a presentation equipped by a visually presented report-making format, Micmac assisted policy makers to report a concensus and justification of the participant of group discussion briefly. The explanation presented by Micmac's analysis was created a greater confidence in result, giving a greater confidence in the problems solving and presenting assumptions were needed explicitly[5].

The Micmac method application was started from defining the problem, identifying internal and external variables and analyzing the variable relationship of system was studied. The next stage was to assess relationship according to the mobility level and variable dependency. At this stage, variables were qualificated according to the influence level, range between the following quantitative scales : $0=$ no influence, $1=$ weak, $2=$ moderate, $3=$ strong and $\mathrm{P}=$ potential. Qualification result would identify the key variable relation, yaitu: direct influence variable and indirect influence variable. Direct influence will occured if A influence $\mathrm{B}$, while indirect influence was occured if $\mathrm{A}$ influence $\mathrm{B}$ and $\mathrm{B}$ influence $\mathrm{C}$. By the transitivity process, $\mathrm{C}$ was indirectly influenced by A. Potential influences occur if the influence should have $\mathrm{A}$ on $\mathrm{B}$. Comparison between the classification of direct and indirect influences confirms the importance of certain variables and reveals that these variables may have long-term effects.

The next stage was to analyze the mobility and dependency of variables determined by the variable position in Input-Output quadrant (Fig. 2) in accordance with the level of influence and dependence. The result of this analysis will group variables into five typology: (1) Input variable. The variable was very influential and also independent; (2) Stake variable. This variable was very influential and also dependent. This variable was the most unstable variable due to any influence of them could flow to the entire system; (3) Regulator variable. The variable had a dependency and moderate influence; (4) Autonomous variable. This variable had low potential to produce changes. Autonomous variable had no influence or dependent, it was often described an inertial trend or slightly changed over time; (5) Output variable. This variable had a low influence but was strongly influenced by other variables. The output variable described an impact resulted from other variables, especially input and regulator variables.

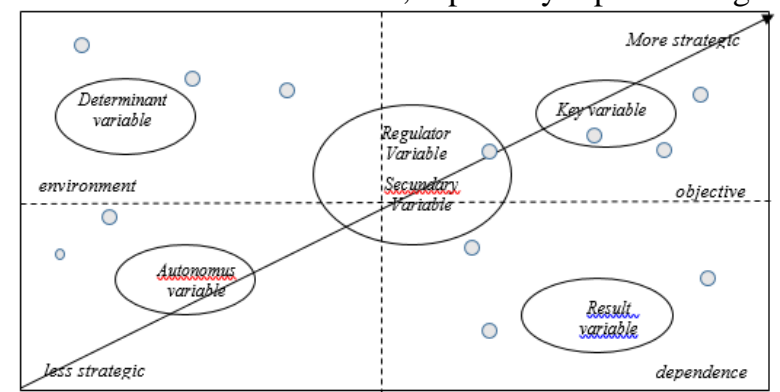

Fig. 2. Variable Clusters According to Input-Output [2];[7] 


\section{Result}

Focus group discussions held were successfully identified the factors assessed by the participants as variables that would determine the success of Kedung Ombo ecotourism region development. The results of the brainstorming produced 33 variables were grouped into six clusters as follow: (1) Natural Cluster, consisting of variables: natural beauty, climate, environmental carrying capacity, integration with surrounding land use, forest preservation and accessibility; (2). Social Cluster, consisting of: community involvement, developer understanding of local norms, potential conflict, employment, community welfare, poverty, preservation of local wisdom, health and security; (3) Economic Cluster, consisting of: tourist market potential, economic potential of tourism business, local entrepreneurship ability, tax, retribution, fund assistance to the community, private investment in tourism sector, allowance to investor and promotion; (4) Institutional Cluster, consisting of: special permit, regulation, coordination and apparatus role; (5) Tourism Cluster, consisting of: local community awareness of tourism, tourist market potential and tourism attraction; (6) Reservoir Function Cluster, namely: conservation of reservoir function; (7) Infrastructure Cluster, consisting of: availability and readiness of tourism infrastructure.

\section{Discussion}

The strategic variables had been assessed by workshop participants consensusly based on its influence intensity. Assessment is done by filling out Matrix of Direct Influence (MDI). MDI produce variable position map of direct influence and direct influenced as in Fig. 3.

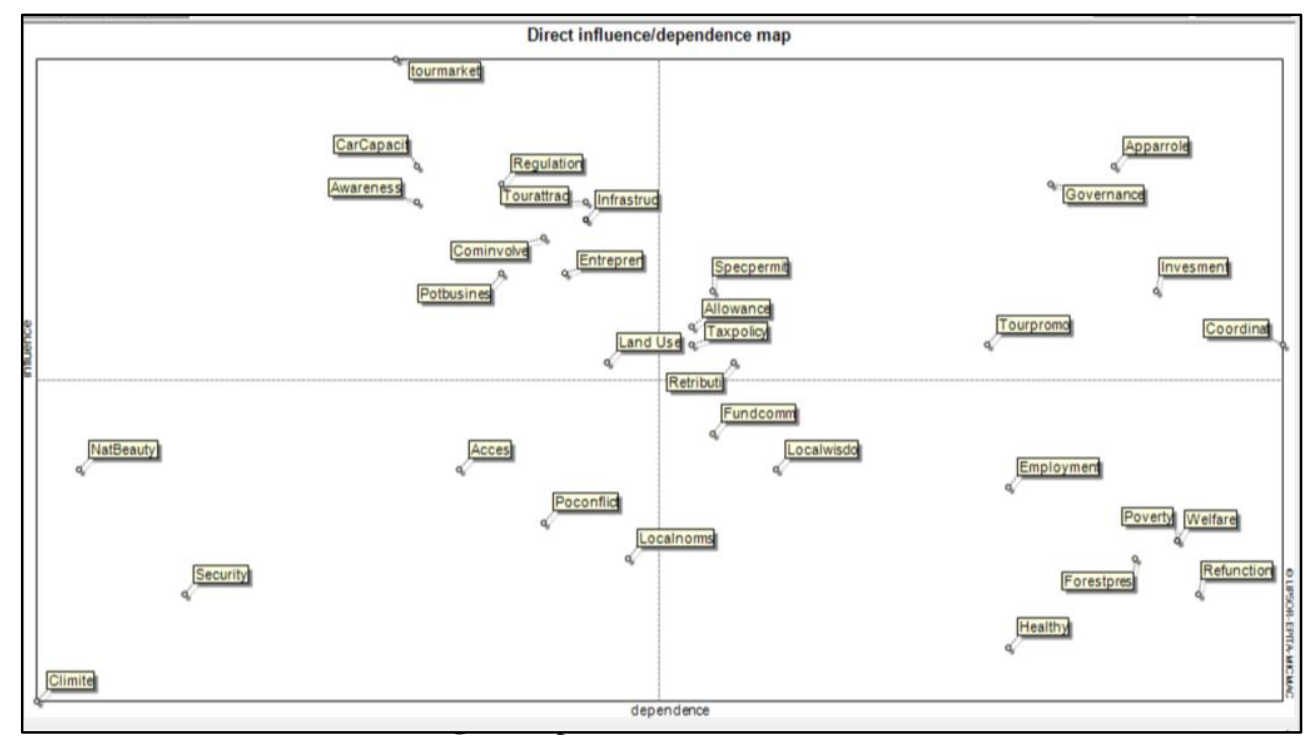

Based on Figure 3, the strategic variable typology of Kedung Ombo ecotourism region can be grouped in the five qualifications as follow:

1. Input variable consist of: regulation, environmental carrying capacity, local awareness of tourism, infrastructure, tourist market potential, tourism attraction, economic potential of tourism business, community involvement, local entrepreneurship ability and integration with surrounding land use; 
2. Key variable (Relay Varible) consist of: special permit policy for investment, retribution policy, tax policy, allowance policy, tourism promotion, apparatus role, governance, private investment, coordination;

3. Autonomous variable consist of: climate, security, natural beauty, accessibility, developer understanding of local norms, potential conflict. In this quadrant there was a variable could be distinguished from other factors, due to its disconnection with other variables. The said variable was called as disconnected variable located near the original axis of the quadrant. For policy application, this variable could be removed from the system dynamic. In this research, there was a typology of disconnected variable, namely climate.

4. The output variable consist of: funds for community, preservation of local wisdom, employment expansion, forest preservation, conservation of reservoir function, welfare improvement and poverty reduction.

5. The regulator variable and secondary variable consist of: special permit, retribution policy, tax policy, allowance policy. In addition there was also secondary variable located in the quadrant of the output variable. Briefly, the analysis result of the direct influence based on MDI matrix could be seen in Table 1.

Table 1 Tipology of direct influence based variable

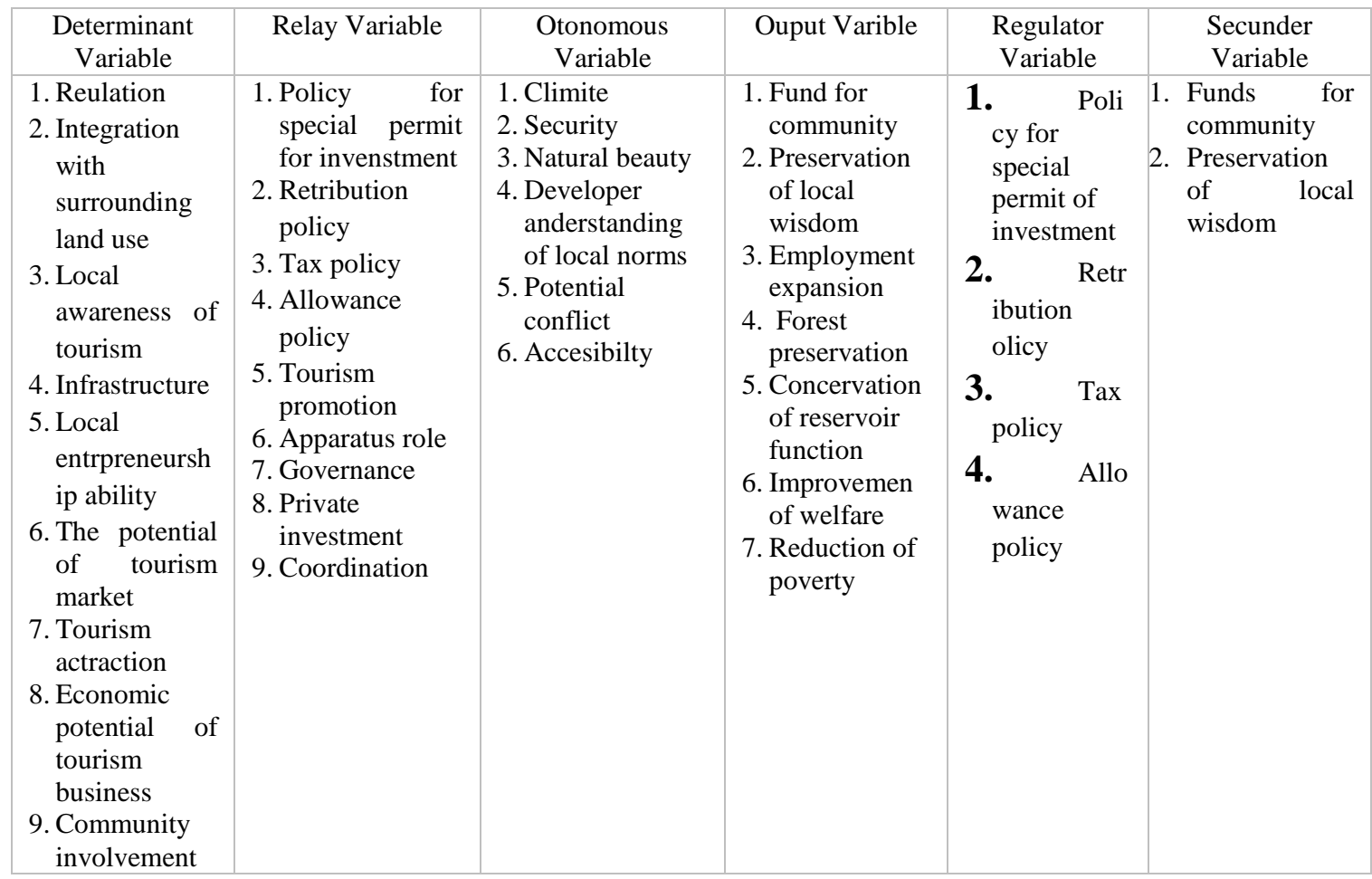

Furthermore, we can see the intensity of the variable influence from the strongest to the weakest. The variable intensity influence was indicated by the line color connecting intervariable, namely: 1) the red line indicated that influence was very strong; 2) the thick blue line indicated that influence was relatively strong; 3) the thin blue line indicated that the 
influence was moderate; 4) the black line indicated that the influence was weak; and 5) the dashed line indicated that influence was very weak. Information of qualification of diret variable influence are very important for policy makers. The result of this analysis could direct the decision makers to focus on variables having the strongest influence, because these variables will determine directly the behavior of other variables.namely: red: shows the influence between other variables is very strong; blue thick line: shows the influence between other variables is relatively strong; blue thin line: indicates influence between other variables being; ash line: indicates influence between other variables is weak; intermittent line shows the influence between other variables is very weak (Fig. 4).

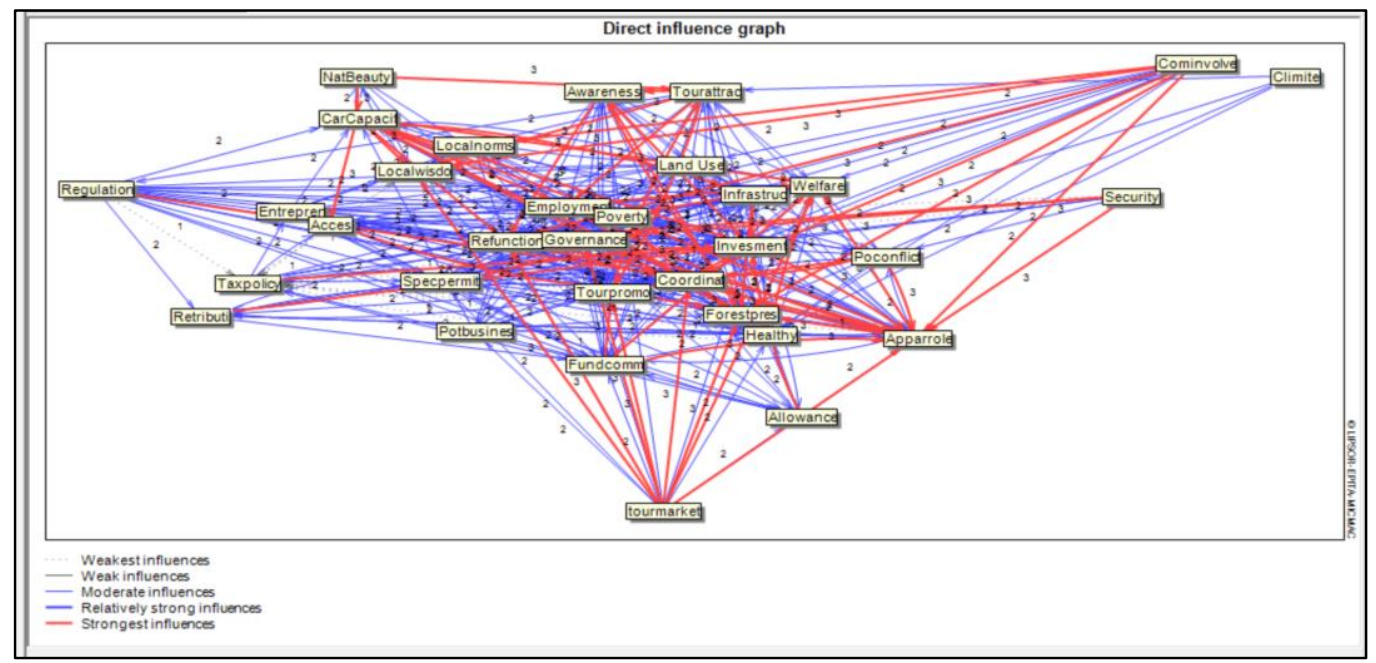

Fig.4. Intensity of direct influence variable

To test the stability of the results of the classification of variables based on direct influence, re-identification is carried out based on indirect influences. The process of analyzing indirect effects is further explained in the matrix MII (Matrix of Indirect Inflations). The results of the analysis of indirect effects will show more satisfying stability in terms of qualifying variables. The output of this indirect classification model will confirm the system stability provided that if there are many changes in the position of the variable from the map of direct influence, then the system has a low stability. The results of the analysis of indirect effects indicate that there is no change in the position of the variable from the direct effect classification. These results indicate that the system and the typology of variables that have been classified in the direct effect are stable. Figure 5 shows a map of indirect influence variables. 


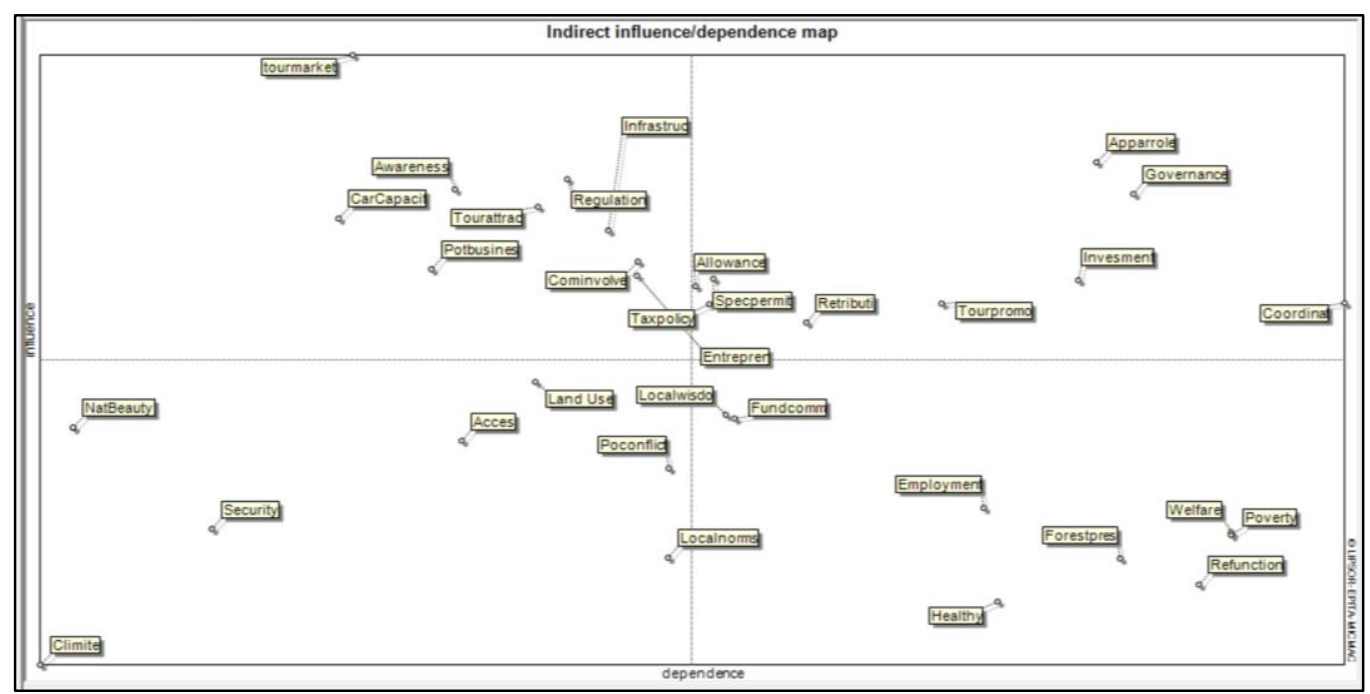

Fig. 5. Map of indirect infleunce variable

However, when viewed from the intensity of its influence, the classification of variables based on indirect influences experienced significant changes. This can be seen from the color change of the line that connects the variable (Fig. 6). From Fig. 6, it can be seen that compared to the direct influence, the analysis of indirect effects is obtained by more variables which have relatively strong influence, while in the direct influence analysis, there are more variables which have a very strong influence.

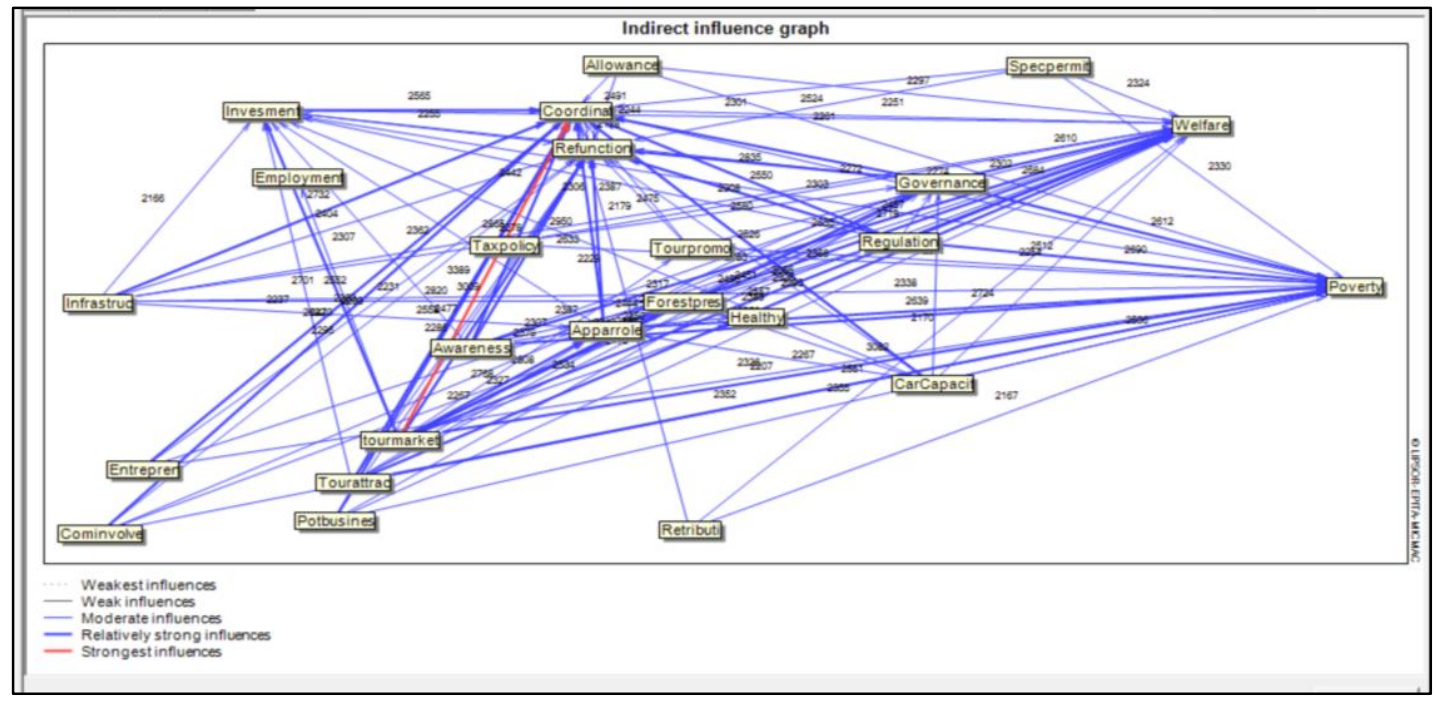

Fig.6. Intensity of direct influence variable 
Furthermore, the MicMac method provides an analysis of potential direct influences that illustrate the possibility of variable classification changes if certain actions are taken on the system. The results of the analysis of potential influences are explained in the Direct Effect Potential Matrix (MPDI) in Fig. 7. From Fig. 7 it can be seen that there is no change in the position of the direct variable influence (Matrix of Direct Influence-MDI) compared to the analysis of the direct effect of variables. From this analysis it can be said that the grouping of variables based on direct influence is stable.

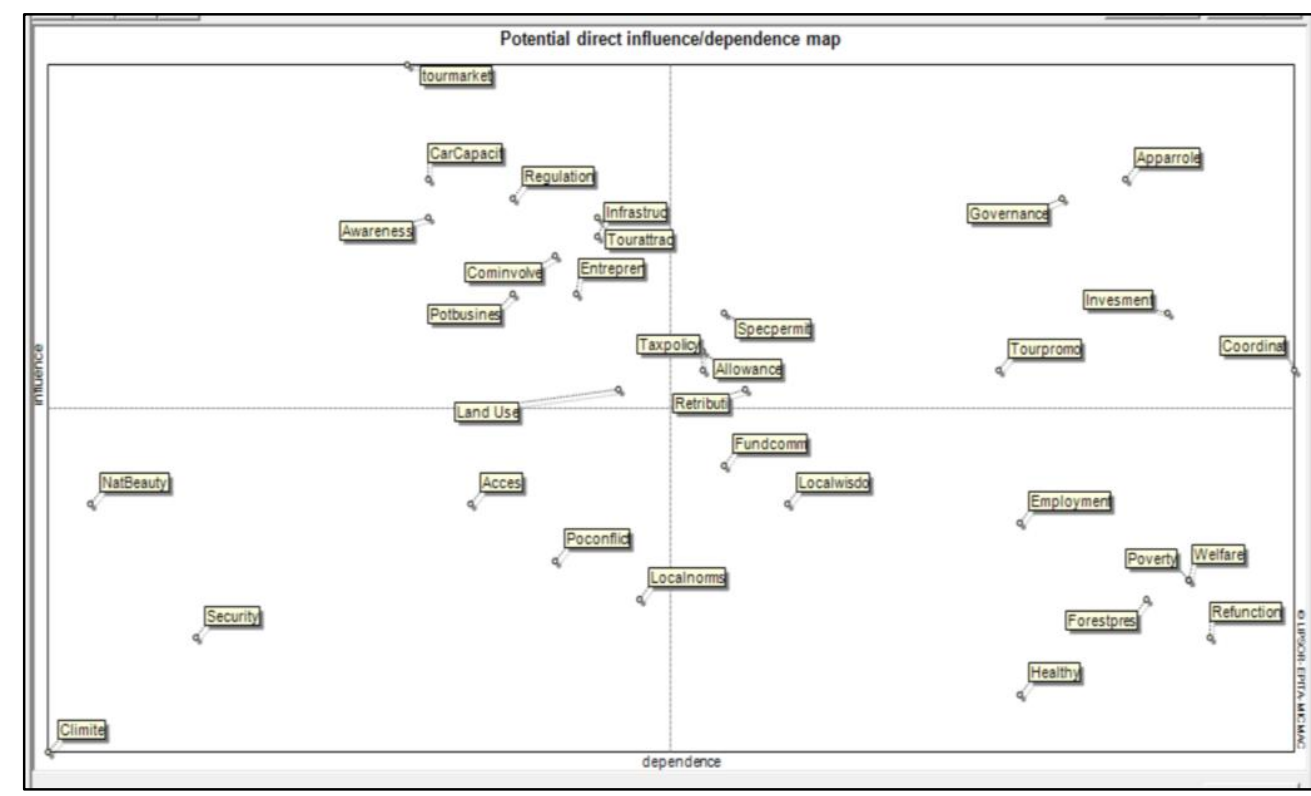

Fig. 7. Map of potential direct influence variable

As we have found in the classification of direct effects, Micmac analysis also provides a potential analysis of the effects of indirect variables, which are referred to as the Indirect Influence Potential Matrix (MPDI). The results of the MPDI analysis are presented in Figure 8. From Figure 8 it can be seen that there is a change in position on the effect of indirect variables, namely on the variable suitability with the use of surrounding land. This variable is in the analysis of direct influence, the potential direct effect and indirect influence are in the input quadrant, whereas in the analysis of indirect potential influence, this variable is in the autonomous quadrant. This change shows that if a policy change for land use is made, the variable can no longer be controlled by the system. This finding is in accordance with the characteristics of autonomous variables located outside the system. However, because the displacement of a position only occurs in one variable, in general the variable grouping that has been done can be said to be stable. 


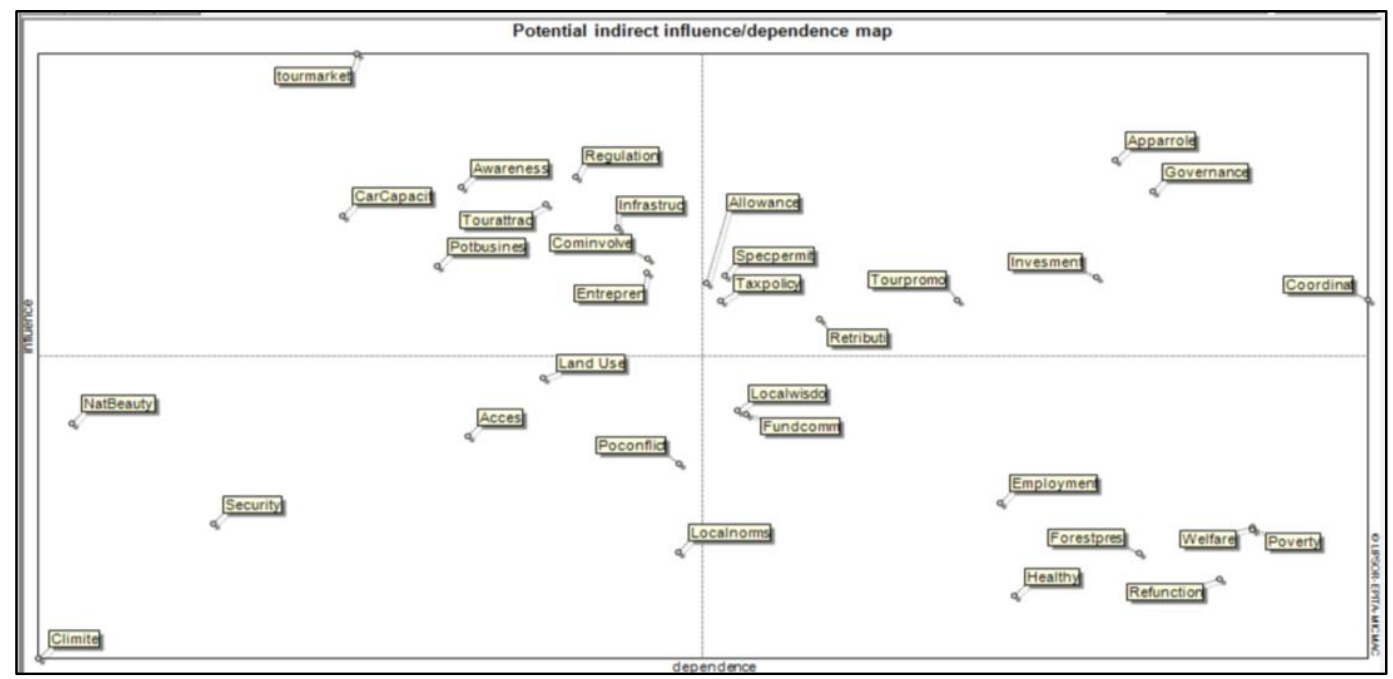

Fig.8. Map of potential indirect influence variable

From the various analyzes that have been carried out, the overall shows that the variable grouping in the development of the ecotourism area of the Kedung Ombo Dam built in this study is stable. This is indicated by the absence of significant changes in the typology of variables from the initial analysis, which is based on direct influence, as well as indirect effects to potential direct effects and potential indirect effects, not significantly changing. Based on these findings, finally we can find out the independent variables and dependent variables in the development system of the Kedung Ombo ecotourism area as shown in Fig. 9 below.
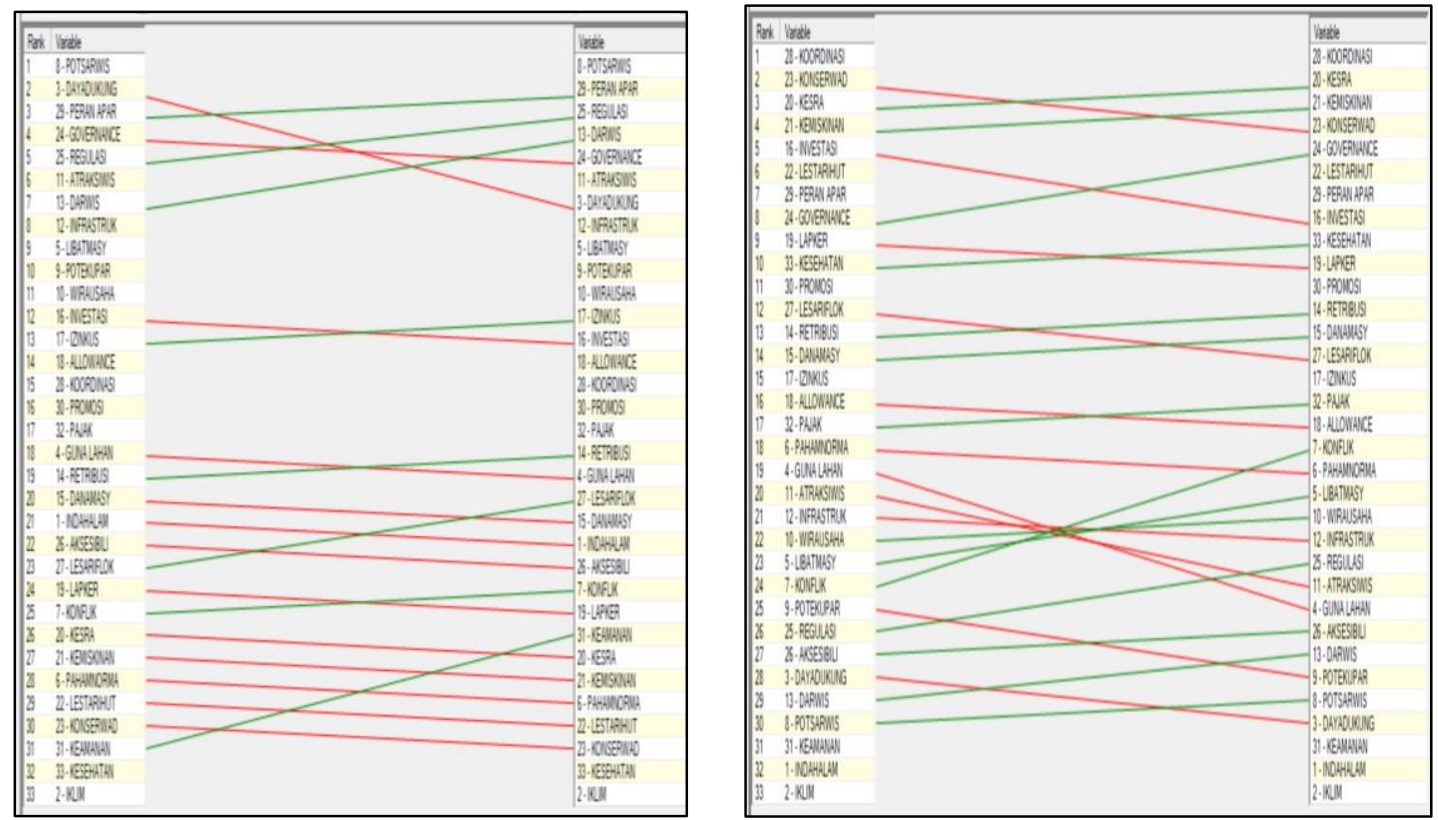

Fig. 9. List of independent and dependent variable 
The findings of this study are very helpful for policy makers in determining on what variables the development policy of the Kedung Ombo region should be focused, where up to now the process has been fully controlled by reservoir operators who tend to prioritize reservoir functions, regardless of tourism potential and interest from Grobogan, Boyolali and Sragen to make it a source of economic and social development which is still the top priority of the three regions.

\section{Conclusion}

The research has succeeded in identifying thirty variables which are considered as the most important variables in the development of the Kedung Ombo reservoir ecotourism area. These variables are spread in various aspects. This finding confirms the initial statement in this study that tourism is a complex system that must be analyzed based on a multidisciplinary approach. After processing using MicMac software, the typology of thirty-three variables was found. This finding is very important for decision makers and will determine the future of Kedung Ombo. The typology is as follows: 9 variables are input variables, 9 variables are relay variables, 6 variables are output variables and 7 variables are autonomous variables (Table 1).Test results on the consistency of these qualifications have been tested and the results are stable.

Among the typologies of variables, variables (relays) must get greater attention from policy makers than other types of variables. Relay variables referred to as betting factors are variables that have high influence and high dependency. This variable will not only provide a boomerang effect but can be an indication of the potential of a system breakpoint. In this study, which included the variable relays were: special permit policies for investment, tax policies, allowance policies, retribution policies, tourism promotion, the role of officials, government, private investment and coordination.

These findings have implications for policy makers developing the Kedung Ombo ecotourism region that they must seriously monitor relay variables and direct all managerial efforts to direct these variables towards the evolutionary path as desired. At the same time, policymakers must also be aware of the relative shortcomings of the current relay variable which is one of the problems that must be resolved to achieve the desired results.

Based on the results of the qualifications of the variables found in this study, especially in relay variables, the potential of ecotourism in the Kedung Ombo Reservoir can still be optimized without having to worry about disturbing the function of the dam. This is because the concept of ecotourism will always maintain a balance between economic, social and natural factors.

Another result of the implementation of prospective structural analysis with the help of the MicMac method on the development of this Kedung Ombo ecotourism area is that institutional aspects are the main aspects that must be emphasized by policy makers. This can be seen in the position of the variables of the role of the government apparatus, governance and coordination variables, which are institutional variables that are at the farthest position from the point of gravity. It can be stated that these variables are the most strategic variables compared to other relay variables.

The development of ecotourism areas based on relay variables will at the same time reduce bureaucratic barriers between reservoir operators, the district government and Perum Perhutani which have become fairly basic institutional problems. The development policy of the Kedung Ombo ecotouriem which considers the findings of this study will produce benefits in expanding work, reducing poverty, conserving forests and conserving reservoir functions as the results of research that classify these variables as output variables. 
This finding is a very strong foundation for all parties involved in policy making to realize a sustainable Kedung Ombo ecotourism area. By understanding the results of this study, all the main stakeholders of the Kedung Ombo reservoir can be involved in the decision making process through the appropriate governance system by economic policies, social policies, land use policies, reservoir conservation policies and a balanced environment.

Finally, we state that the method used in this study is a new way of building a systematic analysis of the role of variables in determining system stability. The application of prospective structural analysis with the Micmac method in the decision-making process that considers the position and intensity of the influence of variables in the form of direct or indirect influence (and no causal relationship) has clarified the validity and strength of the approach in determining the most desired variable involved development of the Kedung Ombo reservoir ecotourism area as expected in the future.

\section{References}

[1] J. Vystoupil, M. Šauer, dan Repík, "Quantitative Analysis of Tourism Potential In The Czech Republic. Acta Universitatis Agriculturae Et Silviculturae Mendekiabnae Brunensis," Number, vol. 65, no. 113, 2017.

[2] S. Delgado, A. M., A., dan F. Amador, Exploring Prospective Structural Analysis to Assess the Relevance of Rural Territorial Development in Spain and Nicaragua. Cuadernos de Desarrollo Rural 12:35-56. 2015.

[3] Q. Zhihai, "Reasonable Development of Tourism Resource of Reservoir A Realization Of Social And Economical Sustainable," Dev. Dep. Civ. Eng. Zhejiang Water Conserv. Hydropower, 2011.

[4] A. Omran, M. Khorish, dan M. Saleh, "Structural Analysis with Knowledge-Based MICMAC Approach,” Int. J. Comput. Appl., vol. 975, no. 8887, Jan 2014.

[5] M. Arias, A. B., J., dan V. Arias, "Structural Analysis of Strategic Variables Through MICMAC Use: Case,” Res. Mediterr. J. Soc. Sci., Jul 2016.

[6] J. Arcade, M. Godet, F. Meunier, dan F. Roubelat, Structural Analysis with the MICMAC Method \& Actors' Strategy with MACTOR Method. AC/UNU Millenium Project. Washington, D.C., USA, 1992.

[7] I. Ghazali, Structural Equations Model Concepts \& Applications with the AMOS 19.0 Program. Semarang: Undip, 2011. 